\title{
Justice Reinvestment as a Global Phenomenon
}

\author{
Ross Homel \\ Key Centre for Ethics, Law, Justice \& Governance \& School of Criminology and \\ Criminal Justice, \\ Griffith University
}

To appear in Victims and Offenders, 9(1), 2014

Accepted for publication October 25, 2013 


\section{Justice Reinvestment as a Global Phenomenon}

Ross Homel, Griffith University

Justice Reinvestment (JR) is an international movement that had its origins in the early 2000s in the United States (Tucker\& Cadora, 2003). From the beginning proponents were animated by data showing that incarcerated individuals come overwhelmingly from the poorest and most marginalized sectors of society, and that there is a remarkable concentration of serious offenders growing up in a relatively small number of communities across the country. Indeed Tucker and Cadora (2003) coined the phrase "million dollar blocks," referring to some small areas in Brooklyn where so many people were in prison that it cost a million dollars a year to incarcerate them. Would it not, these authors opined, make more sense economically and socially to invest directly in these communities to improve living conditions and reduce the risk factors for crime than to continue to pursue a 'fundamentalist' policy of reliance on mass incarceration to improve public safety?

The themes of rational social policy, the intelligent use of data on the geography and sociology of crime, the futility (and, implicitly, the savagery) of imprisonment as a cure-all for crime and safety problems, and the urgent need to rethink policies based on the 'nothing works' mantra are intertwined throughout the debates on justice reinvestment that have spread to many parts of the globe. It is well known that the United States is the incarceration capital of the known universe, and it is this feature of American exceptionalism that seems to give the JR movement in the US particular energy. It is perhaps a little surprising then as the papers in this issue attest - that the ideas of JR have become so popular in 
other countries, such as the United Kingdom and Australia, with growing interest in Europe, South America, China, and other places.

Imprisonment as a default sentencing option has for example never been characteristic of any Australian jurisdiction, despite the nation's origins as a penal colony (Bull, 2010). Indeed, as early as the second half of the nineteenth century several Australian states pioneered the use of such strategies as community service and payment of fines by instalments to avoid sending petty offenders to jail, and were quick to respond to the demands of the child saving movement for humanitarian reforms in how children and young people were treated by the police and courts. Nevertheless, as the articles by both James Austin and Gary Coventry and by William Wood emphasize, thinking Australian have long been extremely concerned about the massively higher imprisonment rates of Aboriginal and Torres Strait Islander (ATSI) peoples, and more broadly about the over-concentration of crime, social and health problems in a relatively small number of localities across all parts of the nation - urban, regional and remote (Allard, Chzanowski \& Stewart, 2012; Gooda, Priday \& McDermott, 2013; Social Inclusion Board, 2011; Vinson \& Homel, 1975; Vinson, 2007). Australians, as William Wood argues, tend to use JR as a convenient rubric to reinforce longstanding arguments for greatly increased investment in evidence-based strategies in disadvantaged communities, and most especially in ATSI communities, in order to 'close the gap' in health, educational and justice outcomes. The conceptual and rhetorical link between de-investing in prisons and re-investing in evidence-based programs for offenders or their communities 
that is such a prominent and seemingly non-negotiable feature of the US movement seems looser, less certain, more debatable in the Australian context.

Certainly in the United States, as the paper by Faye Taxman, April Pattavina and Michael Caudy makes clear, the connection is maintained tightly:

The most recent definition for Justice Reinvestment (JR) supported by the U.S. Department of Justice and its affiliate partners ... is: Justice reinvestment is a data-driven approach to improve public safety, reduce corrections and related criminal justice spending, and reinvest savings in strategies that can decrease crime and strengthen neighbourhoods. (p. $\mathrm{XX})$.

However, there is an identifiable investment decision that needs to be made: do we allocate additional resources for evidence-based programs and strategies designed to change individual offenders, or do we allocate additional resources for a broad range of loosely linked community crime prevention strategies designed to change targeted high risk communities? Assuming that governments will not do both, it seems logical to ask: Which approach will yield the higher return on investment?

There is no simple answer to this question. The problem is, as James Austin and his colleagues have emphasized (Austin, Cadora et al., 2013; Austin \& Coventry, this issue), the cash transfer side of JR has not yet happened, there is little discernible reduction in incarceration rates, community-based services have not been expanded, and "practices in areas of high concentration of populations under control of the justice system" have not been affected (Taxman et al., this issue, p. XX). Does all this make JR a failure as either an individual 
treatment or a community crime prevention strategy? It may be too soon to offer a definitive assessment, but as Austin and colleagues (2013) have noted, "The lack of targeted reinvestment in high incarceration communities is probably the most glaring weakness of JRI"(10). A similar assessment of the lack of targeted reinvestment in individual offender treatment is included in Taxman, et al.'s article. Taxman and her colleagues argue strongly that for the promise of JR to be realised there must be "a commitment to providing theoretically-sound, evidence-based correctional programming in both incarceration and community settings" (p. XX). They propose four performance measures (the validity of which is supported by a series of simulation analyses) to monitor progress in this regard: (1) availability of EBP practices in the system, (2)participation rate, (3)access rate, and (4) responsivity rate.

A distinctive feature of the Taxman paper is its emphasis on extending the reach of evidence-based offender treatment programs, and particularly on matching offenders to programs based on a risk-needsresponsivity assessment. Extending the use of evidence-based treatment and making it more effective is certainly a major preoccupation of JR advocates in every country. However, there is considerable variation from country to country in how this priority goal is being pursued. In China, as Spencer Li's article shows, there has been a very rapid expansion of community-based corrections since the early 2000s. A major reason for this expansion was the growing recognition of the cost and ineffectiveness of imprisonment, despite the fact that China, for social and cultural reasons, has much lower recidivism rates than the West. Although the discourse of justice reinvestment does not appear to be part of the 
official lexicon in China, it is clear that at least to some extent policy makers intended that the expansion of community corrections would lead to reductions in imprisonment rates, would save money since community corrections is cheaper, and would reduce rates of recidivism, especially for drug offenders for whom the mandatory prison-based treatment programs are deemed a complete failure with $90 \%$ recidivism rates. Unfortunately no rigorous evaluations of community corrections have been undertaken, no official data are available on recidivism rates from these programs, and from what can be gleaned from current official statistics, there has been no decline in prison numbers. In other words, despite the clear justice reinvestment objective, what may in fact have been achieved in China with the expansion of community corrections in the last decade is simple net widening, a phenomenon very familiar to Western audiences. However, it should be emphasized that at this is simply conjecture, since the necessary research has not been done.

Several conclusions can be drawn from the comprehensive analysis of crime rates and crime policies across a large number of European countries presented by Santiago Redondo and Nina Frerich, this issue. Perhaps the clearest conclusion is that Europe, home of the Enlightenment, has no uniform commitment to policies based on science or on humanitarian values. The continent is characterized by enormous diversity in crime rates, fear of crime, and punitive policies, with the Mediterranean countries for example making relatively greater use of imprisonment despite low to moderate crime rates (although their imprisonment rates are lower than in Eastern Europe). 
Nevertheless there is a rich tradition of European research on the effectiveness of offender treatment programs, including "a remarkable range of systematic reviews and meta-analyses from almost three decades ..." (p. XX) and the authors argue, in effect, that this resource should become much more prominent in crime policy development. They point to the low imprisonment rates in the Nordic countries despite sometimes rising crime rates, and the commitment in those jurisdictions to the use of scientific research and civilised criminal justice practices. They especially emphasize that at a time when most of Europe is still struggling with the consequences of the Global Financial Crisis, it makes good economic sense to de-invest in prisons and follow once again the advice of reformers such as Cesare Lombroso who were amongst the first to argue that offenders can indeed be reformed using scientific methods.

Kevin Wong, Chris Fox and Kevin Albertson, writing in this issue from an "austere" part of Europe, the United Kingdom, describe how in that country "Payment by Results" (PbR) for the rehabilitation of offenders has gained currency as a "radical and decentralising reform which ... will make the concept of justice reinvestment real by allowing providers to invest money in the activity that will prevent offending rather than spending money on dealing with the consequences" (Ministry of Justice 2010, cited in Wong et al., p. XX). In some ways PbR could be interpreted as a 'put up or shut up' challenge to the advocates of evidence-based policies and JR more broadly, including the NGOs (nongovernment organizations) that claim that they can do much better than government departments in working effectively with offenders. However, a major philosophical problem that this writer has with $\mathrm{PbR}$ and its twin sister, 
Social Impact Bonds, is that they are partnerships “... in which philanthropic funders and impact investors-not governments - take on the financial risk of scaling up" (McKinsey \& Co., 2012). Apart from the fact that this introduces a strong incentive to falsify or manipulate outcomes, it seems grossly unfair to transfer risk in this way when governments themselves have, over many years, failed to invest in the critical R\&D to put offender rehabilitation on a sustainable foundation for large scale delivery, investing heavily instead in imprisonment and other punitive policies that are entirely without scientific foundation and in fact are known to increase recidivism. It appears that governments are willing to invest in prison and control-based community sanctions, but that they want the private sector to invest in strategies designed for individual and community change.

An even bigger problem with $\mathrm{PbR}$ identified by Wong and his colleagues is that it is a strategy that is narrowly focused on criminal justice system redesign rather than on social justice, although they emphasize that these two models are at different ends of a continuum and are not mutually exclusive. By the social justice approach they mean the kinds of policies and practices that in the words of the British Parliamentarian Rob Allen "improve the prospects not just of individual cases but of particular places," and which by working in a flexible and holistic fashion through agency partnerships address the root causes of crime and help stop offending in the first place. In other words, the social justice approach is about 'neighborhood strengthening' as envisaged by the U.S. Justice Department, but it is also ultimately about reductions in social inequality as well as in the manifold injustices and iatrogenic practises embedded in the 
justice system. James Byrne (2008) has expressed well the tension between the system redesign and social justice approaches:

Until we address the underlying community factors that social ecologists have long argued are associated with crime - including location in highrisk neighborhoods, culture, resource availability, jobs, poverty, and a breakdown of informal social control mechanisms - even high-quality, resource-rich rehabilitation programs are not likely to result in broadscale desistance from crime among individual offenders (p. 270)

Byrne's challenge strikes me as being central to the justice reinvestment enterprise, no matter what country is being discussed. But can governments, which in recent decades have become much more interested in managing crime and public risks than in addressing its causes (Bull, 2010), be persuaded to invest heavily even in the rehabilitation of individual offenders, let alone the transformation of the communities from which many of them come? And is social science actually up to the challenge? Our prevention science colleagues are struggling with what they call 'Type 2 translation research and systems,' which is concerned with understanding and building the complex processes and systems through which evidence based initiatives are adopted, implemented and sustained on a large scale (Spoth et al., 2013). They have however made much good progress, and I would suggest a strong alliance between the social ecologists that Byrne refers to and those skilled in prevention science, particularly those from the health sector who have had more success than we have had so far in criminology. I am moreover sufficiently parochial to suggest that Australia could take a lead in this regard, especially in the light of William 
Woods' perceptive analysis of the receptive nature of Australian social policy and the extraordinary opportunities for bold but scientifically founded innovations in ATSI communities (Gooda et al., 2013).

We do need, however, a reality check. Community transformation and reductions in social inequality take years, while the pathway into prison becomes ever more heavily trafficked on a daily basis in many parts of the world. As James Austin and Gary Coventry observe, "The U.S. industrial correctional complex is larger and even more expensive than ever," (p. XX) and there is precious little evidence that so far JR has made much of a dent in this complex. They argue that the 'solution' to America's mass incarceration problem consists simply of "eliminating the use of incarceration for sanctioning most criminal offenses" - in other words, the U.S. should become more like Australia, the UK, the Nordic countries; indeed more like almost anywhere else.

Of course the proponents of JR in the U.S. hoped that this could be achieved by moving money from prisons to either individual or community rehabilitation. This may yet happen, especially if the rational and wellresearched approach advocated by Faye Taxman and colleagues is taken seriously. Nevertheless, I cannot help but think that the reinvestment foundations of JR should be conceptualized as parallel rather than as tightly connected policies: send many fewer people to prison and adopt the Byrne/Taxman models, but don't expect savings from the correctional budget to be moved magically to high-risk communities or to rehabilitation. If we make social justice and crime prevention objectives dependent on criminal justice system reform, history suggests we may well be doomed to failure. 


\section{References}

Allard, T., Chzanowski, A., \& Stewart, A. (2012). Targeting crime prevention to reduce offending: Identifying communities that generate chronic and costly offenders. Trends \& issues in crime and criminal justice no. 445. Canberra: Australian Institute of Criminology.

Austin, J.; Cadora, E.; Clear, T.R.; Dansky, K.; Greene, J.; Gupta, V.; Mauer, M.; Porter, N.; Tucker, S. and Young, M.C. (2013). Ending mass incarceration: Charting a new justice reinvestment. http://sentencingproject.org/doc/publications/sen Charting\%20a\%20New \%20Justice\%20Reinvestment.pdf

Australian Social Inclusion Board. (2011). Breaking cycles of disadvantage, Commonwealth of Australia: Canberra.

Byrne, J. (2008). Editorial introduction: The social ecology of community corrections - Understanding the link between individual and community change. Criminology and Public Policy, 7(2), 263-274.

Bull, M. (2010). Punishment and sentencing: Risk, rehabilitation and restitution. South Melbourne: Oxford University Press

Gooda, M.; Priday, E. and McDermott, L. (2013). Looking beyond offenders to the needs of victims and communities. Indigenous Law Bulletin, 8(5), 13-16.

McKinsey \& Co. (2012). From potential to action: Bringing social impact bonds to the US. https://mckinseyonsociety.com/social-impact-bonds/

Spoth, R.; Rohrbach, L.A.; Greenberg, M.; Leaf, P.; Brown, C.H.; Fagan, A.; Catalano, R.F.; Pentz, M.A.; Sloboda, Z.; Hawkins, J.D. \& Society for Prevention Research Type 2 Translational Task Force. (2013). Addressing core challenges for the 
next generation of Type 2 translation research and systems: The translation science to population impact (TSci Impact) framework. Prevention Science 14, $319-351$

Tucker, S.B. and Cadora, E. (2003). Justice reinvestment. New York: Open Society Institute.

Vinson, T. (2007). Dropping off the Edge: the distribution of disadvantage in Australia. Melbourne: Jesuit Social Services and Catholic Social Services Australia.

Vinson, T. and Homel, R. (1975). Crime and disadvantage: the coincidence of medical and social problems in an Australian city. The British Journal of Criminology, 21-31. 